\section{A Keystone Flap as a Reconstructive Option for Selected Areas: A Prospective Study}

\section{Abstract}

A very few flaps would be described as versatile as the Keystone Flap. The flap was described by Behan in 2003. The keystone flap derives its name from its similarity to the architectural keystone piece that marks the central portion of the arch. It employs immediately adjacent skin and soft tissue that provides a good colour match in addition to reconstructing the contour of the defect, so providing a far superior cosmetic result. A prospective study was developed from October 2017 to December 2019 at SMS Hospital, Jaipur. In our experience, we have observed flap execution is easier over the trunk, gluteal region and thigh, but difficult over knee and distal leg due to deficient skin laxity in the lower leg. It is an excellent option for covering large defects over the thigh where there is adequate tissue laxity. It is a safe option for conditions where microsurgery may not be a viable option. The relative simplicity of this flap makes it to go option at many places.

Keywords: Keystone flap; Reconstruction; Musculocutaneous perforators

Received: May 16, 2020; Accepted: July 14, 2020; Published: July 21, 2020

\section{Samarth Gupta*, Abhishek Sharma and Sunil Srivastava}

\author{
Department of Plastic Surgery, SMS Hospital, \\ Jaipur, India
}

*Corresponding author:
Dr. Samarth Gupta

$\equiv$ samarth.4@gmail.com

Tel: +919727777026

Department of Plastic Surgery, SMS Hospital, Jaipur, India.

Citation: Gupta S, Sharma A, Srivastava S (2020) A Keystone Flap as a Reconstructive Option for Selected Areas: A Prospective Study. J Aesthet Reconstr Surg Vol.6 No.2:6

\section{Introduction}

The keystone island flap was described by Behan in 2003 [1]. The Keystone perforator island flap is a Type A fasciocutaneous advancement flap, consisting of two $\mathrm{V}$ to $\mathrm{Y}$ advancement flaps. Based on fasciocutaneous perforators, the keystone island flap offers both the robust vascularity of perforator flaps and relative ease and speed of local tissue rearrangement [2]. The keystone flap derives its name from its similarity to the architectural keystone piece that marks the central portion of the arch. It employs immediately adjacent skin and soft tissue that provides a good colour match in addition to reconstructing the contour of the defect, so providing a far superior cosmetic result [3]. Blood supply to the flap is based on random vascular perforators, with a dual supply from both the subcutaneous vascular plexus and perforating vessels in the fascial and muscular layers.

Four types are described. In the classical technique, very limited elevation of the flap from its bed is performed. Perforators from the bed of the flap are presumed, but never identified. Keystone flaps have come up as the chief local option for reconstruction of various defects over the trunk [2]. However, difficulties have been encountered in using this flap for lower extremity reconstruction. This study reports our experience using Keystone Flap.

\section{Materials and Methods}

A prospective study was developed from October 2017 to December 2019 at SMS Hospital, Jaipur. The following information was gathered: demographic data, diagnosis, location and size of defect and flap, area of the flap attached to the bed, surgical time, hospitalization time, and complications. Perforators over the leg were Doppler marked preoperatively.

\section{Surgical technique}

Incision is made all along the flap boundary as marked before which is shown in the figure. The incision is deepened until deep fascia, which is also divided all along the outer border. Undermining of the flap border should not be done to prevent injury to fasciocutaneous and musculocutaneous perforators. Minimum undermining can be done on the other side of the defect if there is any tension in the suture line. First suture is taken at the centre of the flap where there is maximum tension. The remaining part of the flap is properly sutured to the defect, closure of the " $Y$ " limb and rest of the flap on the outer border is done using standard technique. Keystone flap should be designed on that side of the defect having maximum skin expansibility. Double flaps may be required to cover larger defects or where 
there is less expansibility of adjacent skin. This flap survives based on perforators emerging from the underlying tissue. Figure 1 shows a diagrammatic representation of the flap.

\section{Results}

50 patients were included in the study. Ages of the subjects were ranging from 18 to $65 \mathrm{y}$ with an average of 38.75 y. 10 cases in our series had distinct risk factors like smoking (30\%), diabetes $(25 \%)$ and radiation therapy (15\%). Among the defects, 25 were following trauma (50\%), 10 defects were due to tumour resection (20\%), 15 were due to debridement of abscesses. The largest defect covered by keystone flap in our series measured $50 \times 20$ $\mathrm{cm}$ and the smallest defect covered was $8 \times 4 \mathrm{~cm}$. The average intra- operative time required to complete the flap was $50 \mathrm{~min}$ (range 20-90 $\mathrm{min}$ ). 30 key stone flaps were done to cover lower limb defects, 10 flaps were done for upper limb defects and the remaining 10 were for trunk defects. The average hospital stay was 3 days. All subjects were followed until they achieved stable, healed wounds. Regarding complications, partial flap necrosis was observed in 2 cases which required skin grafting. 3 other cases had wound infection leading to wound dehiscence, which required secondary suturing. The overall success rate was $95 \%$.

\section{Discussion}

The keystone perforator-based flap is best suited for a defect in the shape of a vertical ellipse with its long axis parallel to the tibia. Such is the ingenuity of the keystone-design that the reorientation of local tissue is akin to performing three V-Y flaps [4].

Advantages are:

(1) Replacement of like with like,

(2) Absence of dog ear,

(3) Preservation of multiple perforators ensuring flap survival,
(4) Usage of the best flap design for local tissue recruitment, and

5) Potential for primary closure of even the secondary defect (albeit only in the upper half of the leg).

Keystone Island flaps can be classified as follows [1]:

Type I: Standard flap design without division of deep fascia.

Type II: The deep fascia on the convex aspect of the flap is divided to enhance mobilization. Further sub categorization (Type II a) secondary defect is closed primarily and (Type II b) secondary defect is closed with a splint skin graft.

Type III: Double keystone flaps are designed to facilitate closure, one on either side of the defect.

Type IV: Up to two- thirds of the flap is undermined. Flap mobilization is maximized.

In our experience, we have observed flap execution is easier over the trunk, gluteal region and thigh, but difficult over knee and distal leg due to deficient skin laxity in the lower leg. It is an excellent option for covering large defects over the thigh where there is adequate tissue laxity.

Keystone flap should be attempted with caution in areas of least skin expansibility - around the knee joint, ankle joint, around the elbow joint, plantar aspect of foot and palmar aspect of hand

It has been reported that keystone flaps around the elbow, knee, and ankle joints should be used cautiously due to reduced skin laxity and a risk of dehiscence [5], and previous studies have reported wound dehiscence following full flexion at the lumbosacral area [3]. Short surgical times without complex intrasurgical or postsurgical monitoring, a single operative field, and a more "stable" perfusion are some of the additional advantages of KF that reduce morbidity, mortality, and intrahospital stay. This differs from the

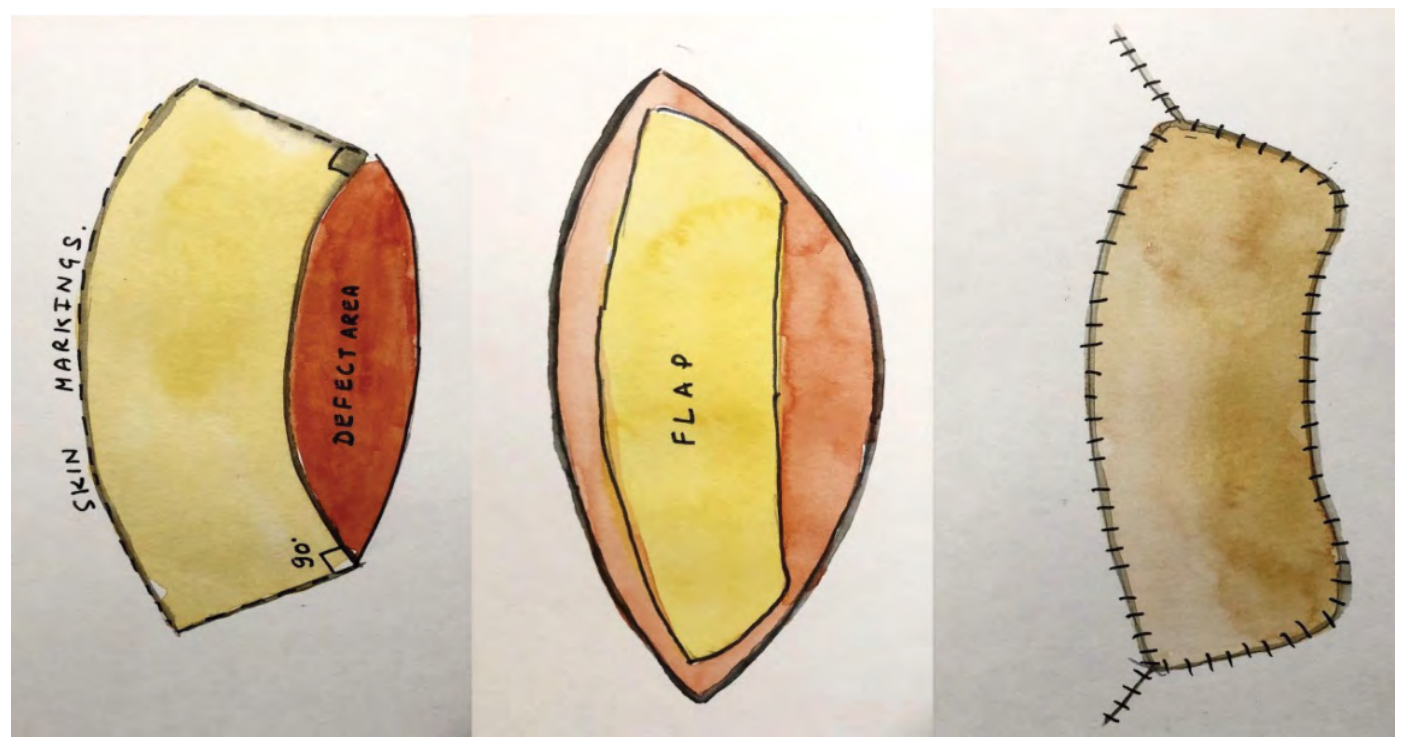

Figure 1 Diagrammatic representation of a keystone flap. 


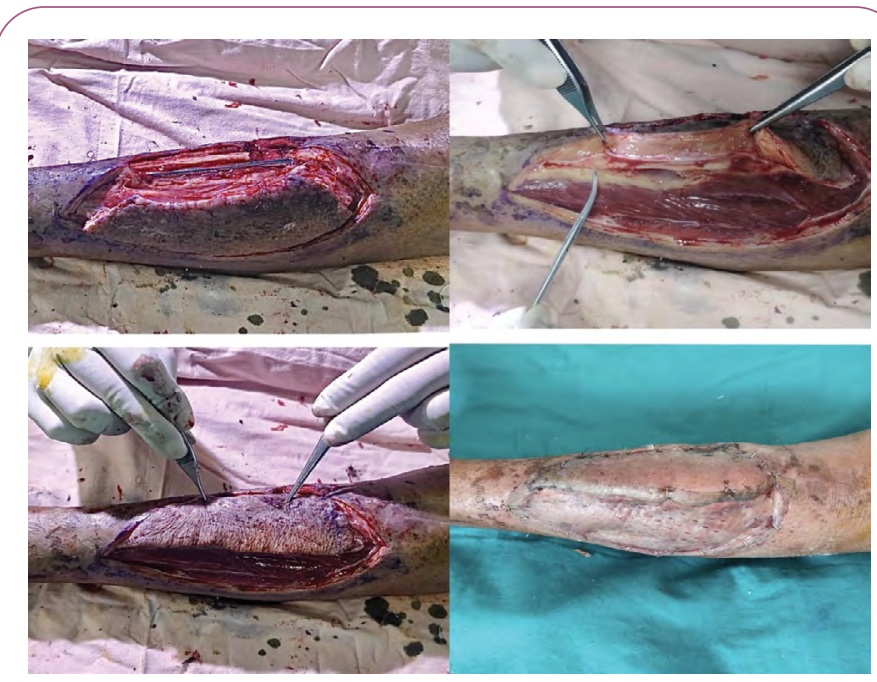

Figure 2 Flap design and plan.

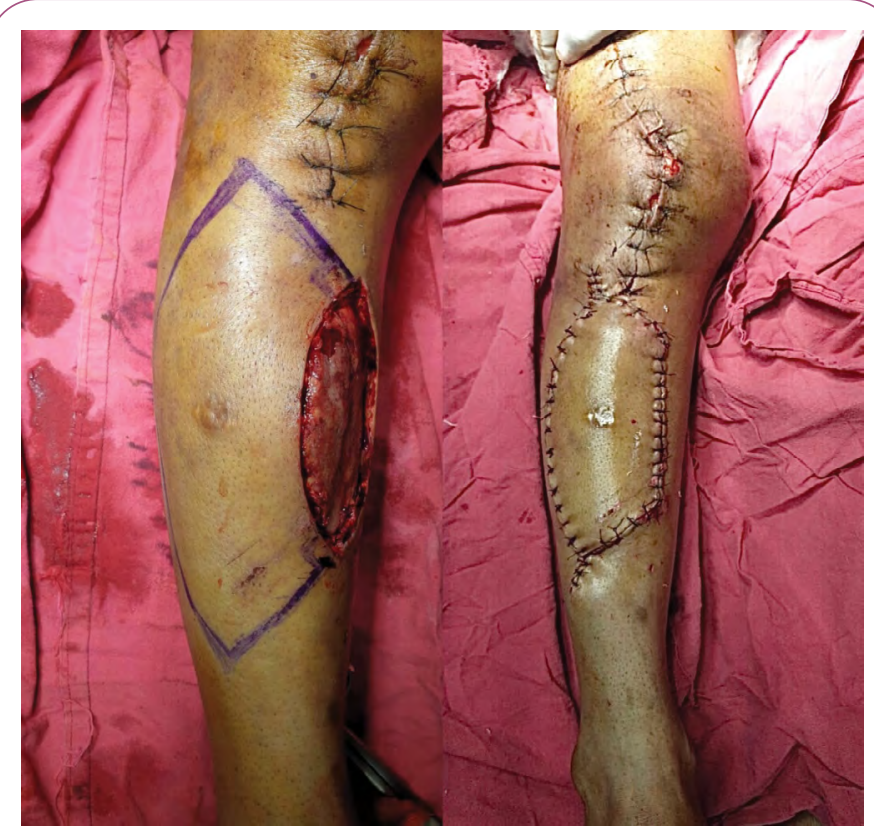

Figure 3 Flap design in another patient.

\section{References}

1 Behan FC (2003) The keystone design perforatoris land flap in reconstructive surgery. Anz J Surg 73: 112-20.

2 Khouri JS, Egeland BM, Daily SD, Harake MS, Kwon S (2011) The keystone island flap: use in large defects of the trunk and extremities in soft-tissue reconstruction 3: 1212-1221

3 Behan F, Sizeland A, Porcedu S (2006) Keystone island flap: an alternative reconstructive option to free flaps in irradiated tissue. Anz J Surg 76: 407-413.

4 Pelissier P, Gardet H, Pinsolle V (2007). The keystone design perforator island flap. Part II: clinical applications. J Plast Reconstr Aesthet Surg 60: 888-891. microvascular options that require a wide learning curve and large resources for its execution. KF technique has limitations. Its efficiency in intraoral and intranasal coverage has not been sufficiently proven. Its fasciocutaneous and musculocutaneous nature lacking bone components excludes them from scenarios with these specific requirements. Besides, due to its vascular dependence on perforators, caution should be exercised in areas surgically or traumatically dissected $[6,7]$. As in any other technique, the design of the island must be careful to avoid transgression of natural folds or scar location on areas of excessive pressure. To do so, it is recommended to design larger islands as previously mentioned (Figures $\mathbf{2}$ and $\mathbf{3}$ ).

We have described keystone flaps for defects on the legs, but the literature has examples of other uses [8]: in ophthalmology for eyelid reconstruction [9], in maxillofacial surgery for parotid defects [10], in general and gynecological surgery for perineal and vulvar defects [11], and in neurosurgery for defects in the dorsolumbar and lumbosacral area $[12,13]$.

In sum, KF"s versatility, functional and aesthetic results, and low complication rate ( $3 \%$ to $4.6 \%$ ) have far exceeded the expectations of any random perforator or flap [14-17]. The KF allows reconstruction in a single surgical time and is a relatively easy and fast technique for the beginner and the experienced surgeon [18-20].

\section{Conclusion}

Keystone flaps provide an effective means of periarticular wound closure in an area of high mobility and low skin laxity. It is an excellent versatile flap that has been put into use at many places. It is technically less challenging and suitable for even those who do not have an experience in microsurgery. Locoregional fasciocutaneous wound coverage offered by keystone flaps provide a good cosmetic match, robust soft tissue coverage and avoid contour defects and contracture at a cost of minimal donor site morbidity.

5 Pelissier P, Santoul M, Pinsolle V (2007) The keystone design perforator island flap. Part I: anatomic study. J Plast Reconstr Aesthet Surg 60: 883-887.

6 Kostopoulos E, Casoli V, Agiannidis C (2015) The keystone perforator island flap in nasal reconstruction: an alternative reconstructive option for soft tissue defects up to $2 \mathrm{~cm}$. J Craniofac Surg 26: 1374 1377.

7 Behan FC, Rozen WM, Wilson J (2013) The cervico- submental keystone island flap for locoregional head and neck reconstruction. J Plast Reconstr Aesthet Surg 66: 23-28.

8 Behan F, Findlay M, Lo CH (2012) The keystone perforator island flap concept. Elsevier, USA.

9 Loh IW, Rozen WM, Behan FC, Crock J (2012) Eyelid reconstruction: 
Expanding the applications of the keystone perforator island flap concept. Anz J Surg 82: 763-764.

10 Behan FC, Lo CH, Sizeland A, Pham T, Findlay M (2012) Keystone island flap reconstruction of parotid defects. Plast Reconstr Surg 130 36e-41e.

11 Behan FC, Rozen WM, Azer S, Grant P (2012) Perineal keystone design perforator island flap for perineal and vulval reconstruction. Anz J Surg 82: 381-382.

12 Jamjoom H, Alnoman H, Almadani Y (2016) Closure of a large thoracolumbar myelomeningocele using a modified bilateral keystone flap. Plast Reconstr Surg Glob Open 4: 1114.

13 Park HS, Morrison E, Lo C, Leong J (2016) An application of keystone perforator island flap for closure of lumbosacral myelomeningocele defects. Ann Plast Surg 77: 332-336.

14 Moncrieff MD, Bowen F, Thompson JF (2008) Keystone flap reconstruction of primary melanoma excision defects of the leg-the end of the skin graft? Ann Surg Oncol 15: 2867-2873.
$15 \mathrm{Hu}$ M, Bordeaux JS (2012) The keystone flap for lower extremity defects. Dermatol Surg 38: 490-493.

16 Kwon S, PC Neligan (2011) The Keystone island flap: use in large defects of the trunk and extremities in soft tissue reconstruction. Plastic \& Reconstructive Surgery 127: 1212-1221.

17 Behan FC, Lo CH, Sizeland A (2012) Keystone island flap reconstruction of parotid defects. Plast Reconstr Surg 130: 36e-41e.

18 Behan FC, Rozen WM, Azer S (2012) Perineal keystone design perforator island flap for perineal and vulval reconstruction. Anz J Surg 82: 381-382.

19 Khouri JS, Egeland BM, Daily SD (2011) The keystone island flap: use in large defects of the trunk and extremities in soft-tissue reconstruction. Plast Reconstr Surg 127: 1212-1221.

20 Rao AL, Janna RK (2015) Keystone flap: versatile flap for reconstruction of limb defects. J Clin Diagn Res 9: PC05-PC07. 